\title{
Impact of the UK lockdown on people at risk of COPD
}

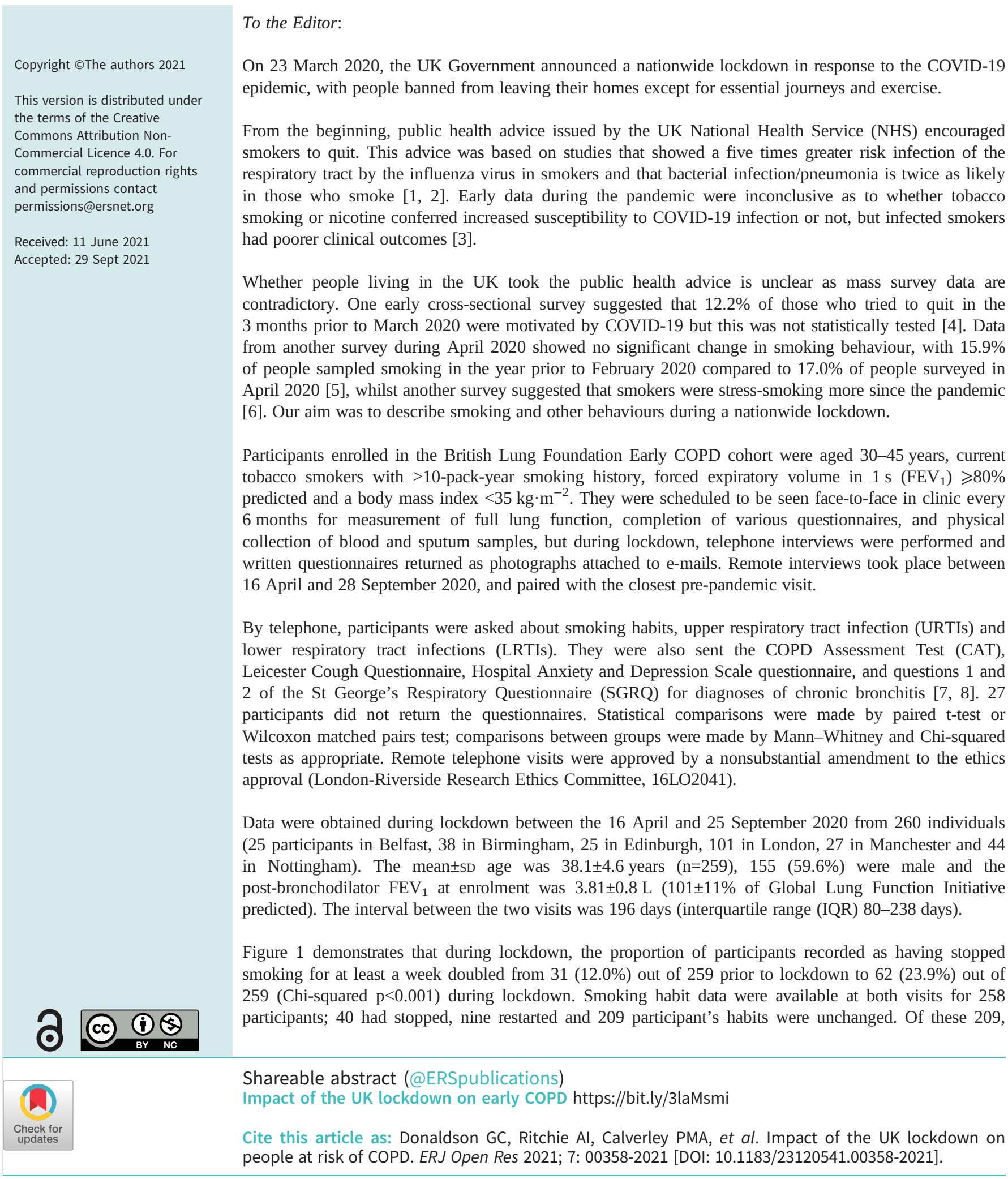



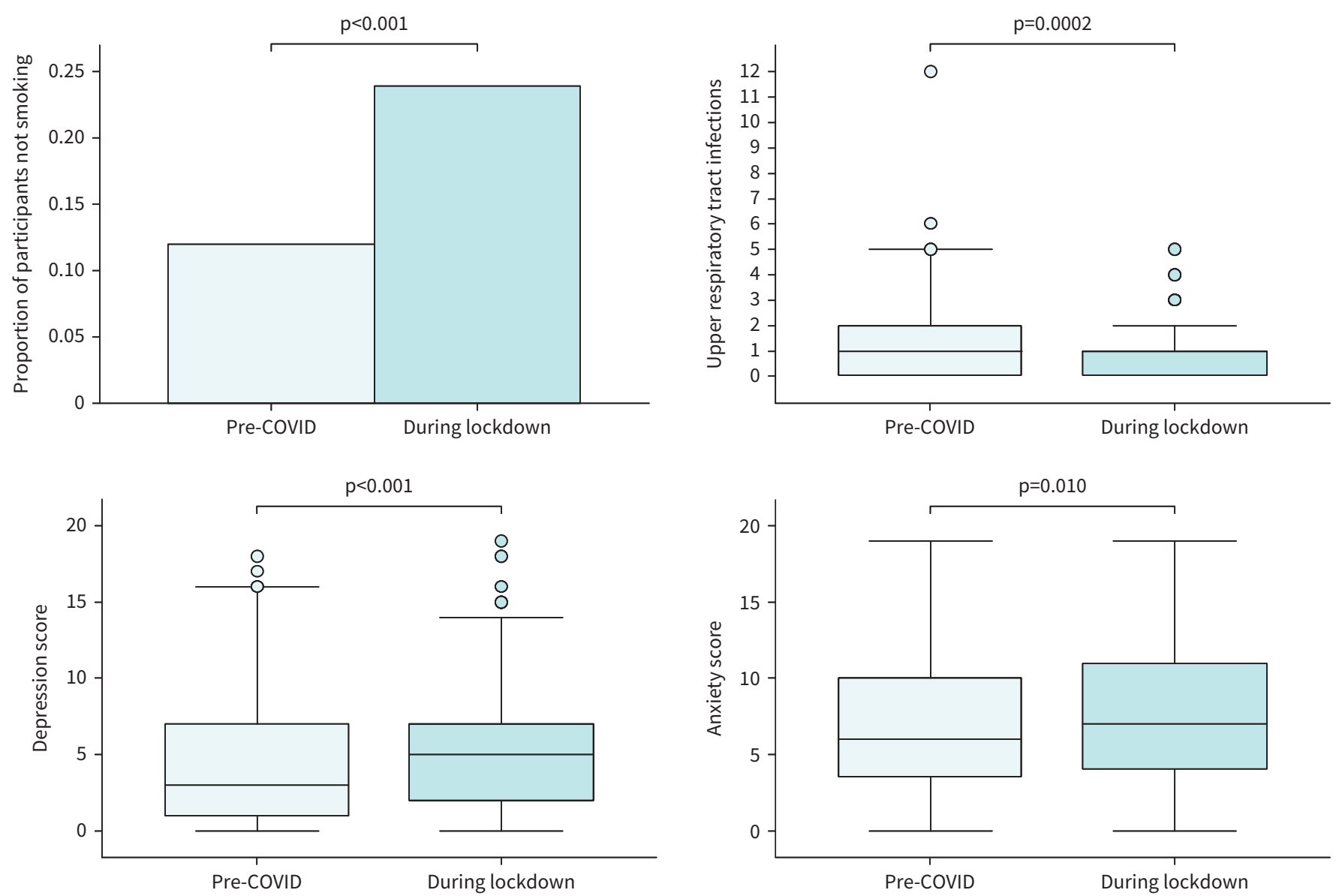

FIGURE 1 The proportion of nonsmoking participants, frequency of upper respiratory tract infections, and depression and anxiety scores before and during lockdown in the UK during the COVID-19 pandemic.

187 continued to smoke and 22 had already quit. In those who smoked before and during lockdown, assessed over the 7 days preceding each visit, tobacco consumption (cigarettes per day; Wilcoxon $\mathrm{p}=$ 0.587 ) and rolling tobacco (grams per week; Wilcoxon $\mathrm{p}=0.924$ ) was unchanged.

During lockdown, the anxiety component scores increased from $6.7 \pm 4.4$ to $7.4 \pm 4.7$ ) ( $\mathrm{n}=233$; t-test $\mathrm{p}=0.010)$ and depression scores increased from $4.30 \pm 3.9$ to $5.14 \pm 4.1)(\mathrm{n}=233$; t-test $\mathrm{p}<0.001)$. Anxiety increased in 78 out of 233 and depression in 89 out of 233 participants by $\geqslant 2$ units, the minimally important difference in COPD [9].

Respiratory symptoms improved during lockdown, with CAT scores falling from 9 (IQR 6-15) to 8 (IQR 5-13) ( $\mathrm{n}=233$; Wilcoxon $\mathrm{p}=0.008)$ and the total Leicester Cough Questionnaire score indicating improvement, as it increased from 19.7 (IQR 17.6-20.6) to 20.0 (IQR 18.7-20.8) (n=204; Wilcoxon $\mathrm{p}=0.045)$.

A comparison of the 40 patients who quit during lockdown with those 187 who smoked at both visits showed no difference prior to lock down in CAT scores (Mann-Whitney $\mathrm{p}=0.814$ ) or in the prevalence of chronic as bronchitis defined by the SGRQ (Chi-squared $\mathrm{p}=0.607$ ). However, after quitting, CAT scores were lower (5 (IQR 3-13) compared with 9 (IQR 6-13)) in smokers (Mann-Whitney p=0.0307) and chronic bronchitis less prevalent (four $(11.8 \%)$ out of 34 ) than in those who continued to smoke (47 (28.1\%) out of 167) (Chi-squared $\mathrm{p}=0.045)$.

The number of URTIs recalled by the participants fell from a median of 1 (IQR 0-2; group mean 1.24) when asked pre-pandemic to a median 1 (IQR 0-1; group mean 0.84) (Wilcoxon $\mathrm{p}=0.0002$ ) when asked during lockdown. There was no difference in the number of LRTIs (Wilcoxon $\mathrm{p}=0.192$ ). 
In summary, during the UK national lockdown and a period of enforced social distancing, there was a significant increase in the proportion of 30-45-year-old smokers who quit smoking despite increased levels of depression and anxiety. It has been reported that depressed individuals are more likely to be nicotine dependent but paradoxically, older depressed adults coupled with health concerns are more motivated to quit [10]. Stress may have enhanced lockdown as an important moment at which to quit. One limitation in our study is the absence of objective measures of nicotine use. However, participants who self-reported that they had quit smoking had a reduced prevalence of chronic bronchitis and lower CAT scores, which suggests they were truthful about their habits. There was also a reduced number of URTIs, again suggestive that participants had fewer social interactions and opportunities for cross-infection.

Our findings suggest that any evaluation of the health response to the pandemic needs to balance deterioration in mental health in specific age groups with improvements in respiratory health.

Gavin C. Donaldson ${ }^{1}$, Andrew I. Ritchie ${ }^{1}$, Peter M.A. Calverley ${ }^{2}$, Jorgen Vestbo $\oplus^{3}$, Malin Fageras ${ }^{4}$, Alberto de la Hoz ${ }^{5}$, Enrica Bucchioni ${ }^{6}$, Chris H. Compton ${ }^{7}$, Karen Mezzi ${ }^{8}$ and Jadwiga A. Wedzicha ${ }^{1}$ on behalf of the BLF Early COPD Partnership

${ }^{1}$ National Heart and Lung Institute, Imperial College London, London, UK. ${ }^{2}$ University Hospital Aintree, University of Liverpool, Liverpool, UK. ${ }^{3}$ Division of Infection, Immunity and Respiratory Medicine, University of Manchester, Manchester, UK. ${ }^{4}$ Astra-Zeneca, Gothenburg, Sweden. ${ }^{5}$ Boehringer Ingelheim International GmbH, Ingelheim am Rhein, Germany. ${ }^{6}$ Chiesi, Parma, Italy. ${ }^{7} \mathrm{GSK}$, Brentford, UK. ${ }^{8}$ Novartis Pharma AG, Basel, Switzerland.

Corresponding author: Gavin C. Donaldson (gavin.donaldson@imperial.ac.uk)

Provenance: Submitted article, peer reviewed.

BLF Early COPD Partnership: G.C. Donaldson, A.I. Ritchie, F. McLean, L. Moreira (both Imperial College London, London, UK), B. King (University of Belfast, Belfast, UK), K.P. Yip (University of Birmingham, Birmingham, UK), A.S. Beech, A. Bikov (both University of Manchester, Manchester, UK), S. Ferguson (University of Edinburgh, Edinburgh, UK), C.W. Kong (University of Southhampton, Southampton, UK), C. Holmes (University of Manchester, Manchester, UK), A.R. Jenkins (University of Nottingham, Nottingham, UK), A. Deans (University of Edinburgh, Edinburgh, UK), M. Fageras, A. de la Hoz, E. Bucchioni, C. Compton, A. Hamblin, A. Mackay (AstraZeneca), M. Kots (Chiesi), K. Mezzi, D. Mohan (GSK), I. Bottoli (Novartis), I. Jarrod, N.Snell (both British Heart Foundation, London, UK), E. Hoffman, J. Atha (both University of Iowa, lowa City, IA, USA), J. Allinson (Imperial College London, London, UK), C.E. Bolton (University of Nottingham, Nottingham, UK), P.M.A. Calverley, G. Choudhury (University of Edinburgh, Edinburgh, UK), L. McGarvey (University of Belfast, Belfast, UK), E. Sapey (University of Birmingham, Birmingham, UK), T.M.A. Wilkinson (University of Southampton, Southampton, UK), J. Vestbo and J.A. Wedzicha.

Conflict of interest: G.C. Donaldson reports grants from AstraZeneca, and personal fees from AstraZeneca, the American Thoracic Society, FWO Flanders and Novartis, outside the submitted work. A.I. Ritchie has nothing to disclose. P.M.A. Calverley reports grants and personal fees from GlaxoSmithKline, personal fees from AstraZeneca, Boehringer Ingelheim, Phillips Respironics, Novartis, Recipharm and Zambon, and personal fees and nonfinancial support from Boehringer Ingelheim outside the submitted work. J. Vestbo reports personal fees from AstraZeneca and Boehringer Ingelheim, grants from Boehringer Ingelheim, and personal fees from Chiesi, GSK, Novartis and TEVA, outside the submitted work. M. Fageras has nothing to disclose. A. de la Hoz reports a salary from Boehringer Ingelheim International. E. Bucchioni is an employee of Chiesi. C.H. Compton is an employee of and holds shares in GSK. K. Mezzi is a Novartis Pharma AG employee. J.A. Wedzicha reports grants from GSK, meeting expenses only (no personal fees since January 2015) from Novartis, Boehringer Ingelheim and AstraZeneca, and a grant from Chiesi outside the submitted work.

Support statement: The study is funded by AstraZeneca, Boehringer Ingelheim, Cheisi, GSK and Novartis. Funding information for this article has been deposited with the Crossref Funder Registry.

References

$1 \quad$ Arcavi L, Benowitz NL. Cigarette smoking and infection. Arch Intern Med 2004; 164: 2206-2216.

2 Stämpfli MR, Anderson GP. How cigarette smoke skews immune responses to promote infection, lung disease and cancer. Nat Rev Immunol 2009; 9: 377-384.

3 Vardavas Cl, Nikitara K. Covid-19 and smoking: a systematic review of the evidence. Tob Induc Dis 2020; 18: 20. 
Tattan-Birch H, Perski O, Jackson S, et al. Covid-19, smoking, vaping and quitting: a representative population survey in England. Addiction 2021; 116: 1186-1195.

5 Jackson SE, Garnett C, Shahab L, et al. Association of the COVID-19 lockdown with smoking, drinking and attempts to quit in England: an analysis of 2019-20 data. Addiction 2021; 116: 1233-1244.

6 Mintel Press Office. Panic puffs: half of smokers are stress-smoking more since the pandemic started. https:// www.mintel.com/press-centre/social-and-lifestyle/panic-puffs-half-of-smokers-are-stress-smoking-more-sincethe-pandemic-started. Date last updated: 15 April 2021.

7 Kim V, Zhao H, Regan E, et al. The St. George's respiratory questionnaire definition of chronic bronchitis may be a better predictor of COPD exacerbations compared with the classic definition. Chest 2019; 156: 685-695.

8 Kim V, Crapo J, Zhao H, et al. Comparison between an alternative and the classic definition of chronic bronchitis in COPDgene. Ann Am Thorac Soc 2015; 12: 332-339.

9 Wynne SC, Patel S, Barker RE, et al. Anxiety and depression in bronchiectasis: response to pulmonary rehabilitation and minimal clinically important difference of the hospital anxiety and depression scale. Chron Respir Dis 2020; 17: 1479973120933292.

10 Sachs-Ericsson N, Schmidt NB, Zvolensky MJ, et al. Smoking cessation behavior in older adults by race and gender: The role of health problems and psychological distress. Nicotine Tob Res 2009; 11: 433-443. 